\title{
Developing a methodology for preparation and execution phase of construction project
}

\author{
Sonja Kolarić \\ University of Zagreb \\ Faculty of Civil Engineering \\ sonjaa.kolaric@gmail.com
}

DOI 10.5592/otmcj.2015.1.4

Research paper

\section{Keywords}

Bim; Planning; Execution;

Project Management; 5D; Education; Model

\author{
Dragana Pavlović \\ University of Zagreb \\ Faculty of Civil Engineering \\ pavle.dragana@gmail.com
}

\author{
Mladen Vukomanović \\ University of Zagreb \\ Faculty of Civil Engineering \\ mvukoman@grad.hr
}

At the BegINNINg of 2014 EUROPEAN COMMISSION ADOPTED A RESOLUTION ENCOURAGING 28TH MEMBER STATE TO APPLY BUILDING INFORMATION MODELING (BIM) IN PROCURING CONSTRUCTION PROJECTS. As a direct response, many governments of the most developed states within the EU, introduced a short-term goals to make all major projects designed with BIM till the end of 2016. BIM is the most advanced concept in building design modeling that combines professions such as architecture, civil engineering and others. It is widely used around the world; however, in Croatia and in Eastern Europe it is still not as popular as in the most developed countries of the world. In order to improve this described situation we developed a methodology that proved to be applicable in technology and construction management. The same methodology has been validated through the usage in education of the Civil Engineering students. The methodology includes the following steps and software: creating 3D model and quantity list using Autodesk Revit or Nemetschek Allplan software, making cost estimations and time plan using Gala software and finally $5 \mathrm{D}$ simulation that includes cost breakdown using Navisworks software. Through the work we had proved that with applying BIM methodology in construction projects, the participants in the preparation and execution phase can achieve higher productivity and quality of work, collaborate with other participants through interactive work, identify problems in the early phases and achieve higher profits. Furthermore, it has been proved that with the application of BIM methodologies, construction engineers better understand the process of preparing, monitoring and controlling of construction. Although this methodology is validated the future studies should include other BIM tools and investigate their compatibility, involve other resources in the construction simulation and expand BIM education other related technical colleges. 


\section{Introduction}

Building Information Modeling (BIM) content has become the most advanced approach to integrating information in construction projects from very earliest project phases onto the project ed. It combines professions such as architecture, civil engineering and other engineering disciplines. As such in the world has a wide application. However, in Croatia and in Eastern Europe it is still not as popular as in the most developed countries of the world. This situation was the reason to research BIM application by comparing the level of awareness and its application in Croatia with the rest of the world. Great Britain, Netherlands, Denmark Finland and Norway have set short term goals after which all of the procurement will be mandatory to comply with the BIM technology. In 2015 the European Parliament voted in favor of the directive according to which the next two years the member countries will stimulate the application of BIM technology in public works in order to reduce project costs, shorten construction times and modernize the procurement process, whereupon it will be mandatory (StudioARS, 2015).

Through available literature on the application of BIM we analyzed the current situation in world practice and made conclusions about the benefits of the same and considered approach to the business. Such widespread use of BIM technology suggested the advantages of its use Furthermore, the lack of integration and the lack of involvement of participants through all phases of a project was the main reason of this research. This problem causes: cost overruns, non-compliance with the schedule, large costs deviations throughout the life cycle of the building, a number of errors in documentation and inability to control the amount of information. Introducing BIM approach to business is proved to reduce errors and to constantly evolve a more complex cooperation in the virtual environment where the execution of the project is more successful. In addition, we have to mention the problems that remain unexplored, and which are constantly present in the application of BIM in the company business. These are: increased capital expenditures when implementing BIM, large investments in computers and technology that supports all the software tools and the size of files that are created by using BIM, incompatibility of software used for the same purposes and the issue of responsibility for design errors (Eastman, Teicholz, Sacks, Liston, 2011).

To show the real situation regarding the application of BIM technology in Croatia, a survey of the domestic market on the same subject was conducted. The aforementioned advantages presented of the foreign markets research are a clear indication of the necessity to implement BIM technology on the Croatian market, where the same actions would make it more competitive in the global market. This would activate civil engineering profession and raise the Croatian economy from the current recession. BIM provides a significant increase in productivity, more accurate and detailed analysis of the project, quality collaboration, rapid changes, early detection of problems and a host of other benefits that provide a rapid return on investment (Intelika BIM, 2015).

All these facts were the reason for the methodology development of the BIM implementation in education which acquired basic BIM skills, but also knowledge about the proper work and thinking in a collaborative environment where they are left to everyone involved in the process of developing the project. Proper use of this developed methodology is illustrated with concrete examples and the methodology itself is validated through education of students of Civil Engineering in Zagreb. If the developed methodology proved to be successful, methodology steps can be used to further practice in the stages of preparation and execution of the project, but also education.

Therefore, the main objective of this article is to develop a methodology for the correct application of BIM, which will increase the use of BIM in the Croatian construction practice that is currently in very poor condition and which will be applied in the education of engineers. For these reasons the article will be designed in a way that we will initially define the basic problems, hypotheses and objectives of the operation and furthermore we will show the literature review, development of the methodology and validation of the same on real example.

\section{Problems, Objectives And Hypotesis Of The Resarch}

The following research problems were identified that initiated this study:

- low awareness of Croatian civil engineering of BIM issues

- lack of information on the proper application of BIM technology

difficulty to accept the changes and the introduction of innovation in business

weakness of the proper and quality education

non-involvement of state authorities in order to encourage the application of BIM approaches

glut on the market with new technological tools which causes confusion

$\checkmark$ different perspective of the stakeholders

incompatibility of the software used in the same purpose

current lack of integration work professions involved in the development of the project for which the faults occur, project delays and increase costs that exceed the planned budget

For the purposes of this study, we formulated the two main hypotheses of work:

H1: By applying BIM methodology in construction projects, the participants, in the preparatory phase and 


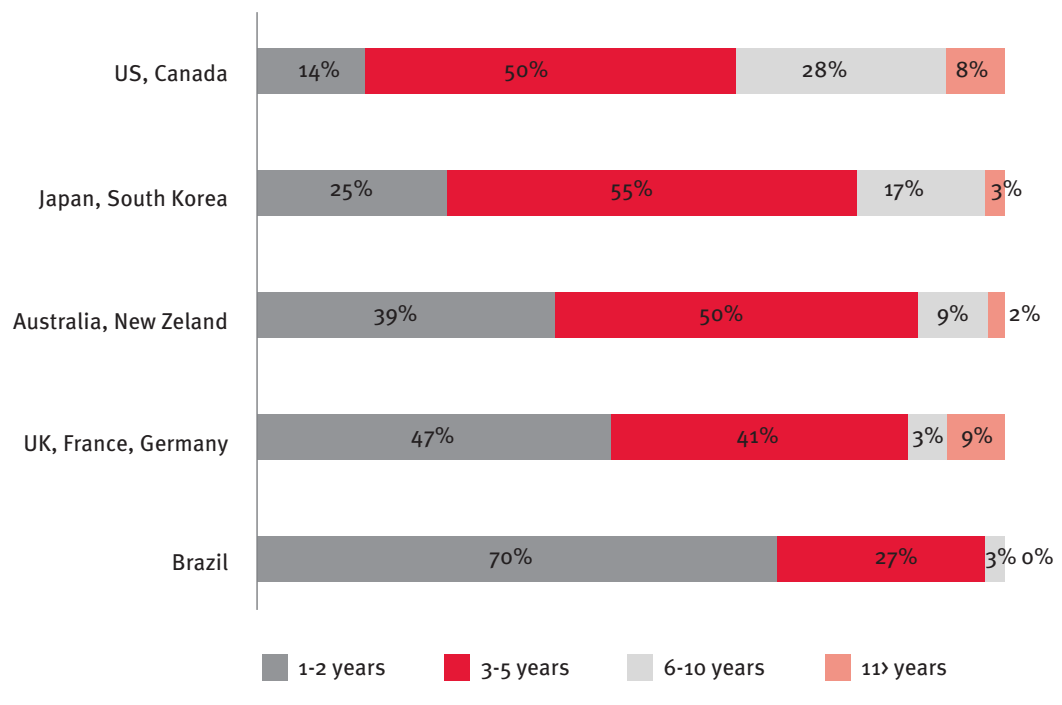

Figure 1. Period of BIM use in companies around the world (McGraw Hill Construction, 2013)

in the execution phase of project construction can: achieve higher productivity and quality of work, have control over all the information and changes within the project early on to identify possible errors, provide more detailed and precise analysis of the project, collaborate with other participants through joint work interactively, and thus achieve a high level of communication, identify problems early in the project, faster and more accurately make cost estimates, control compliance with the schedule, achieve higher profits and faster return on investment.

- H2: By applying BIM methodologies in the education of civil engineers, the students can more efficiently and effectively understand the process of preparing, monitoring and control of construction.

- The above problems and hypotheses of work opened to us the whole topic of research in which will prove them to achieve the following objectives:

- make a comparison of the Croatian and world market investigating companies benefits of BIM

- explore the perception of BIM technology in the construction industry

- develop a methodology for the proper application of BIM applications in the technology and construction management

- prove justification developed methodology through its application in education

\section{Current Resarch}

In order to enter into consideration of these themes is necessary to review current research on the issue of same. The first segment of the current research represent research the market to gain insight into the level of awareness and application of BIM in various countries, the manner of its application, the business benefits that users notice when applying BIM and disadvantages of applications, with the aim of improving the entire approach.

McGraw Hill's Construction research finds out that the Brazil is beginner in the application of BIM where $70 \%$ of companies use this concept 1 or 2 years. European countries have the

\begin{tabular}{|c|c|c|c|c|c|c|c|c|c|}
\hline & France & Germany & Japan & $\begin{array}{c}\text { Aus/ } \\
\text { NZ }\end{array}$ & Canada & US & Brazil & UK & $\begin{array}{l}\text { South } \\
\text { Korea }\end{array}$ \\
\hline Steel Fabricator/ Erector & $66 \%$ & $61 \%$ & $70 \%$ & $51 \%$ & $48 \%$ & $62 \%$ & $37 \%$ & $62 \%$ & $41 \%$ \\
\hline Mechanical/ Sheet Metal/ Plumbing Contractor & $63 \%$ & $61 \%$ & $50 \%$ & $57 \%$ & $38 \%$ & $66 \%$ & $24 \%$ & $24 \%$ & $24 \%$ \\
\hline Electrical Contractor & $77 \%$ & $68 \%$ & $60 \%$ & $36 \%$ & $35 \%$ & $35 \%$ & $16 \%$ & $18 \%$ & $10 \%$ \\
\hline Curtain Wall Fabricator/ Installer & $50 \%$ & $58 \%$ & $43 \%$ & $27 \%$ & $31 \%$ & $21 \%$ & $32 \%$ & $21 \%$ & $35 \%$ \\
\hline Civil/Site/ Geotechnical Contractor & $80 \%$ & $52 \%$ & $57 \%$ & $46 \%$ & $38 \%$ & $12 \%$ & $39 \%$ & $21 \%$ & $7 \%$ \\
\hline Concrete/ Masonry Contractor & $60 \%$ & $50 \%$ & $50 \%$ & $35 \%$ & $8 \%$ & $13 \%$ & $21 \%$ & $13 \%$ & $11 \%$ \\
\hline Drywall/ Ceilings Contractor & $50 \%$ & $58 \%$ & $33 \%$ & $13 \%$ & $19 \%$ & $7 \%$ & $12 \%$ & $8 \%$ & $12 \%$ \\
\hline
\end{tabular}

Table 1. Using BIM considering the given nature of the project (McGraw Hill Construction, 2013) 
same number of those companies who have been applying BIM for 1 - 2 ( $47 \%$ ) and $3-5$ ( $41 \%$ ) years, which also prove recent entry of BIM in UK, France and Germany. Australia, New Zealand, Japan and South Korea have more than $50 \%$ of those who have applied BIM for three years and more, but still cannot be said that this countries are experts in the application of the same. At the top of usage are US and Canada with more than $35 \%$ of companies which have been applying BIM over 6 years, and only $14 \%$ are beginners who use it 1 or 2 years. These facts prove that listed countries have more BIM experts than any other country. This data and more details you can find in figure 1 .

In table 1 it is shown that most of the considered countries have an investment in BIM technology that is more than $50 \%$ of all private investments. Furthermore, the percentage of BIM application in these projects is in direct correlation with the activity of the government and government agencies to promote the adoption of BIM. In United Kingdom, the United States and Canada, where the government introduced mandatory application of BIM during the execution of public facilities, the percentage of applications is very high in comparison with the rest of the country. In case of residential buildings and single-family houses the number of expectedly lower because of smaller projects are less complex and have lower costs (McGraw Hill Construction, 2013).

Due to the unevenness of application of BIM techniques throughout the countries of the world and because of different preferences and knowledge of experts, consequently have evolved standards that balance all of the above. Institutions that help the unification of standards are various government organizations, profit and non-profit organizations, consultants and companies that develop software support. The most important organizations in the development of BIM is considered the International Alliance for Interoperability (IAI), which in 2005 changed its name to buildingSMART. Its main tasks are to deal with improving the exchange of data between multiple applications of the construction industry. BuildingSMART has developed a neutral and free platform Industry Foundation Classes (IFC) with the task of becoming a standard format for all collaborative BIM software. IFC is recognized as an international standard, and is finally registered as ISO 16739. There are currently more than 150 software tools that support IFC (BuildingSMART, 2015).

Its main objective is to achieve universal standards that are applicable in every nation of the world and to connect and cover the visual and structural data. For its development helped many techniques and tools (Fu, C, Aouad, G., Lee, A., Mashall-Ponting, A., Wu, S., 2005). IFC is created in collaboration with an independent, non-governmental International Organization for Standardization (ISO). Beside IFC, listed organizations are created standardized BIM information which are (Hill, T., Steele, R., 2014):

- Base BIM dictionaries -> buildingSMART Data Dictionary (bSDD) -> ISO12006-3,

> Process data -> Manual delivery of information (IDM) -> ISO29481-1.

With the development of these global standards we single out one example of a project created with BIM software together with the application of these standards. Thus we see that the preceding considerations are not just a theoretical thinking, but on the contrary, it is applied to highly complex projects that, without the involvement of BIM approach to the whole process, might not even be able to perform. The mentioned example is the railroad Croassrail, which is one of Europe's largest construction projects and built by a multinational company Arup
Group Limited (ARUP). Named company welcomed the encouragement of the British government that by 2016 BIM techniques should be implemented in all public sector projects (ARUP, 2015). The Crossrail railways construction is underway with currently about 8,000 employees working at 40 sites across the railroad tracks. The planned costs are $f 14.8$ billion and they, together with deadlines, make the biggest risk of the project (MacLennan, P., 2015). The goal of this project is to be the first infrastructure project that is fully integrated through a $3 \mathrm{D}$ model. All elements are optimized in order to ensure lower capital investment and in order to maintain the minimum investment in the railways built in the near future. Trains of the railway will be fully opened to traffic by the beginning of 2020 (Webb, S. 2015).

Results of market research open the second segment, which is the research of BIM software. In doing so, the opinion of those who apply the same become the basic information for the necessary modifications to the tools to be applied, while the functionality of existing software is constantly leads to a greater degree. Moreover, these results allow the development of new businesses BIM tools and expansion of use thereof and to the various other areas. Today, the widespread use of BIM in the field of architecture, structural engineering, MEP (mechanical, electric, plumbing) design and construction until the level of applications in the areas of sustainability and facility management currently is at a slightly lower level. The reason is the late entry of BIM in these areas but also the fact that through the time they get more and more important (Eastman, Teicholz, Sacks, Liston, 2011). Below is a list of BIM software classified in 6 areas of application (table 2 ).

The third segment of the research relates to the proper application of BIM approaches in education. This represents not only the knowledge of the 
individual BIM software, but also the adequate implementation of the same, then the ability to work in a collaborative virtual environment, interoperable cooperation with all those involved in the project. That can also be used in the education of all those who BIM apply. Here we come to the idea of BIM education which represents the application of BIM concept in education in order to acquire skills which are mentioned in the text above and as such are the basic of the correct implementation of BIM. At many universities around the world and Croatia for quite some time, students have been working on projects using 3D models, however, BIM technology is in its full sense rarely used as part of a college education. Most research on the proper application of BIM in education has been conducted on students of architecture. Conclusion is that creating and working with a $3 \mathrm{D}$ model is not as demanding work, on the contrary, quite intuitive job, and students who are computer literate, and it is today most of them, can be done within a few days to fully overcome (Friedrich, Kubečka, 2013). The term BIM education does not mean just creating and working with the $3 \mathrm{D}$ model, but how we can get the information we need for our particular profession in this model and then manage and properly use them. In addition, interdisciplinary environment is one students are not familiar with because within student education do not meet with it (Malachy, 2012). To all of the above correctly transposed to the students we have to observed two things; a curriculum which teachers have to keep and the way that they represent it to the students. In addition, learning should stimulate an objective fact reasoning. The introduction of such an approach in education brings many benefits while more students can work on the same project, work together to solve problems from different fields at the same time from different locations (Elinwa, Agboola, 2012). Furthermore, the introduction of BIM in classes students begin to look critically at their actions because they, in a complex environment, could see how some of their demands can cause various problems in other professions (Fonesca, Villagra, Marti, Redondo, Sanchez, 2012). It was also shown that students learn faster if they were given a realistic project that is taught in the classroom because such cases are better simulate real conditions and facilitate the idea of integration with other projects and optimizing project plans (Peterson, Hartmann, Fruchter, Fisher., 2010).

\section{Metodology Of The Analysis}

We analyzed the Croatian market in order to get insight into the application of BIM technology in Croatia practice. Research was conducted through electronic survey consisting of 16 questions of 3 types: 'yes/no' questions, a choice of answers and providing choice of numbers in Likert scale from 1 to 4 with a possibility to answer 'Not familiar'. The ideas for the concept questions were taken from 'Smart Market Report' published by McGraw Hill house. The result of such structures of the questions are mixed complex of mutually dependent and independent data where we used index of relative importance (RII). RII refers to the value in the interval from o to 1 . The higher value of the RII index is, the more important and better perception it gets. The same is calculated according to the formula:

$$
\mathrm{RII}=\frac{\sum_{\mathrm{W}}}{\mathrm{A} \cdot \mathrm{N}}
$$

$\checkmark W$ is the assessment and response of the individual participants in the survey,

$\checkmark \mathrm{A}$ is the highest score of all participants in the survey,

$\checkmark \mathrm{N}$ is the sum of all participants in the survey (Dolaček Alduk, Z., Radujković, M., Vukomanović, M., 2012).
Through the work we developed a methodology that can be applied to basic education and the stages of preparation and implementation of projects, not only among students, but also among the participants who are involved in project development. All of them who apply the same need to acquire basic knowledge of BIM and use of software so that they can get insight into: 3D models, 'intelligent' facility, collaborative environment, the way of thinking in a virtual environment and $5 \mathrm{D}$ projects. Contemplated software are Excel, Gala, Microsoft Project, Revit, Allplan and Navisworks. We will show 5 combinations of this software.

For the purpose of validation of developed methodology, also for the test of the pilot project performance, we introduced BIM technology within the education of master students of Construction Management course at the. The students were surveyed twice. The first time before the application of BIM and the second after the BIM concept was introduced. The main aim was to show their level of awareness on this topic and the level of satisfaction after they had felt the BIM benefits.

\section{BIM Perception In Croatia}

\section{Descriptive statistics}

The sample of the Croatian market regarding BIM knowledge were 25 employees from micro companies (31\%), 19 (22.9\%) from small companies, 17 (20.5\%) from middle companies and those from large companies $20(24.1 \%)$. Most of the surveyed companies have the smallest income <2 million per year - 37 (49\%). Besides the smallest income companies there were participants who claim that they are from the firms who have profit 2 to 10 million euro's and 10 to 50 million euro's per year-14 (18\%) and those who have 50 million euro's profit per year- 11 (15\%).

$83.1 \%$ of participants were civil engineers while the others are architects 


\begin{tabular}{|c|c|c|c|c|c|c|c|c|}
\hline \multicolumn{9}{|c|}{ Which BIM tools do You know? } \\
\hline & Revit & Civil 3D & $\begin{array}{c}\text { Microsoft } \\
\text { Project }\end{array}$ & Navisworks & Vico & Bentley & ArchiCAD & Nemetschek \\
\hline RII & 0,459 & 0,437 & 0,568 & 0,412 & 0,41 & 0,42 & 0,515 & 0,49 \\
\hline
\end{tabular}

Table 3. Analysis of the answers on the question 'Which BIM software do you know?'

(4.8\%), electrical engineers (2.4\%), geodes (1.2\%), mechanical engineers $(1.2 \%)$ and others represented in small numbers (6\%). The majority of participants in the survey claimed that they are operational manageress (project manager, team member) - 52 (63\%), a little bit less said that they are involved in a high management (administration, executive part) $-23(27.7 \%)$ and just 7 of them ( $8.4 \%)$ are involved in a middle management (department head). We conclude that operational managemeners working on site, contributed most to the survey results. From the perspective of contractors and noncontractors a quarter of participants classified themselves in first group, a tree fourth of them in the second one.

\section{Discussion and result analysis}

The answers showed that more participants knew what the concept of BIM technology means, however, $38 \%$ of all participants who did not know what is the meaning of BIM technology, is a surprisingly big percentage. This is just another indicator of how slow global trends creep into our market. We can conclude that the Croatian construction sector was aware about the BIM technology, but the majority of respondents were not aware of the IT tools on the market nor of their right purpose (this was indicative with the high perception of Microsoft Project as a BIM tool).

Table 3 shows participants perception of the selected IT tools used within the building processes

To analyze the results, we made a new scale from 1 to 5 where 1 means 'Not familiar with', 2 means 'poor performance', 3 means 'average performance', 4 means 'good performance' and 5 means 'excellent performance'. The most frequently used software in the Croatian practice is Microsoft Project (RII=0.568), with whom are familiar two thirds of respondents, and as such received the highest marks but must note how the same is not a BIM software. That fact only confirms that BIM technology in Croatian practice used in a very small percentage. BIM software ArhiCAD $(\mathrm{RII}=0,515)$ is the most used one in Croatia whereby its performance are rated as average and software Nemetcheck $(\mathrm{RII}=0,490)$ with a little bit lower grades of performance.

In the next question we wanted to get a picture of the benefits to the company while implementing BIM in the business which are shown in table 4 .

The scale has been formulated in the following manner. 1 means 'BIM in a particular activity is irrelevant to the activity', 2 means 'BIM importance is taken into account for this particular activity', 3 means 'BIM is applicable in a particular activity', and 4 means 'BIM is a necessary for this activity'. By analyzing the results, and consequently the relative importance index (RII) we see that the advantages of the application of BIM in business Croatian companies is 'Reduction of repetitive and time-consuming procedures' which is rated as the most important priority (RII=0.900), followed by 'Reducing errors' (RII=0.800) and the third prominent advantage states 'Reducing costs

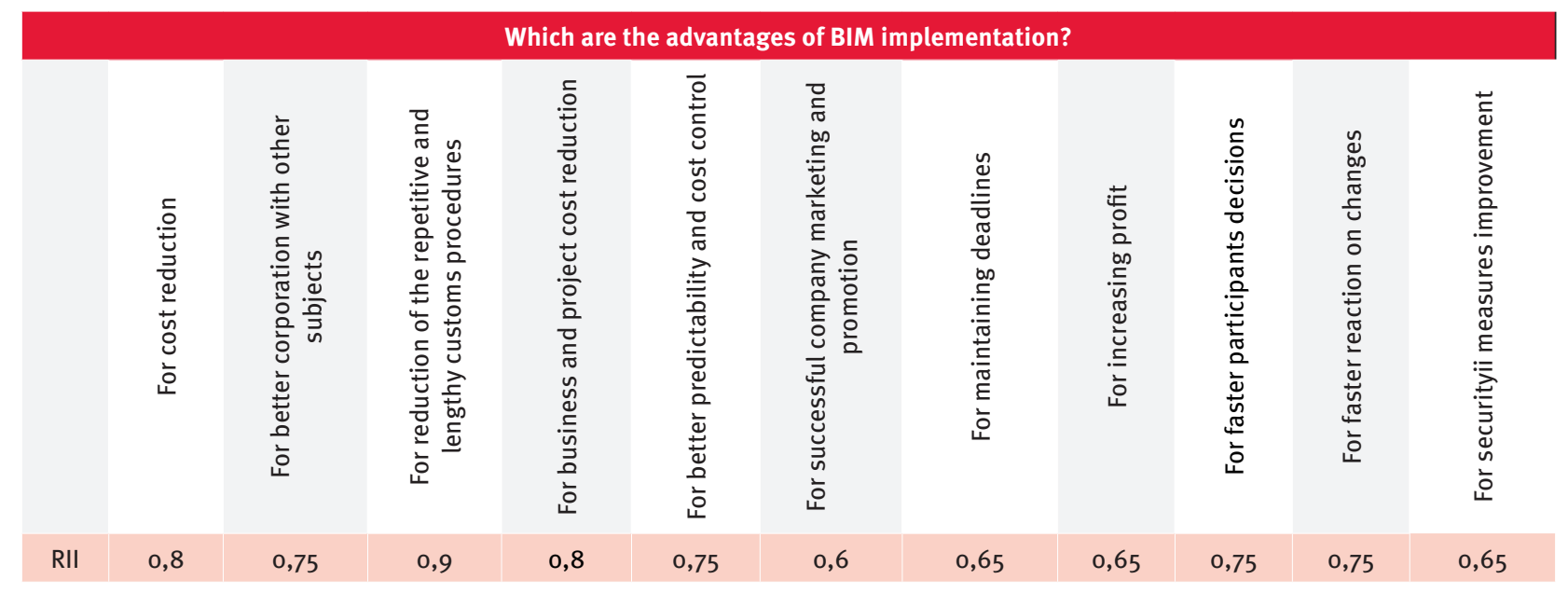

Table 4. Analysis of the answers of the question 'Which are the advantages of BIM implementation?' 
of business and projects' (RII=0.800). The results show that the participants are aware of the benefits that BIM brings; however it is important to consider the fact that few Croatian companies apply BIM properly in their business, so we can still find this singled out benefits, that individual participants gave, just a speculation. The mutual similarity of the results confirms this fact.

\section{Development Of Methodology For The Correct Application Of BIM}

The methodology was developed on the concrete examples of buildings and civil engineering. The study was started with knowledge of Excel and Microsoft Project, and a basic knowledge of Revit, Navisworks, Allplan and Gala and tested in education of the master students of the Construction Management course at the University of Zagreb, Faculty of Civil Engineering. In following section we will show the five combination of BIM we used when developing the methodology for the preparation and execution phases.

\section{The combinations}

Combination 1 - Revit + Excel + Gala Creation process is as follows: making 3D model in Revit, exporting bill of quantities and IFC from Revit, making cost analyzes and estimation with Gala, calculating the activities duration using Excel, connecting the model and costs with plan and finally displaying construction simulation in Gala. In the figure 2 we can see steps of combination 1.

We conclude that Excel is in the process of time planning unnecessary as Gala independently calculates the duration of the activity and the required number of groups. The combination was rejected because of the unnecessary steps and unnecessary inclusion of additional software for calculations of duration.

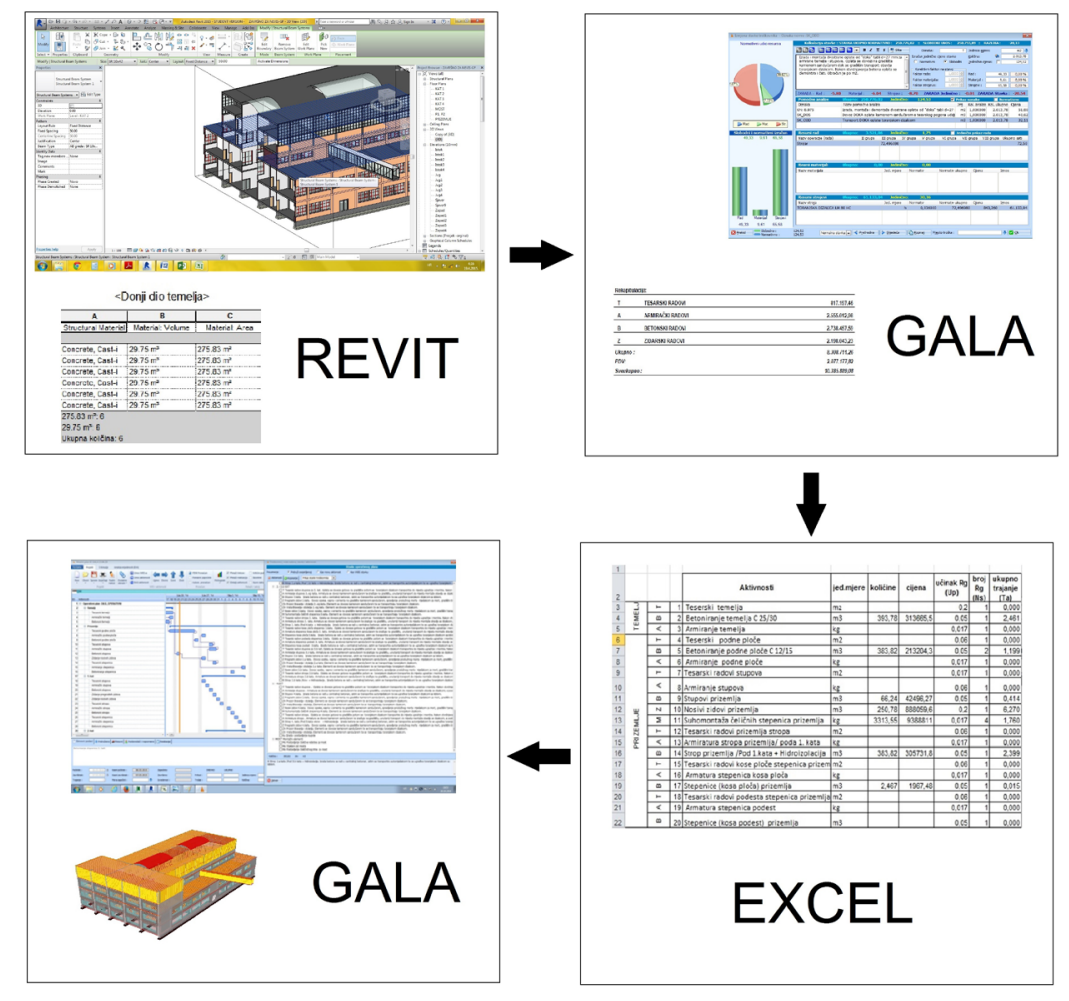

Figure 2. Combination 1

Combination 2 - Revit + Gala

Creation process was as follows: making 3D model in Revit, exporting IFC from Revit to Gala, making bill of cost, time plan and construction simulation uses Gala. In the figure 3 we can see steps of combination 2.

In order to use this combination of software required is extremely wellprepared $3 D$ model and simplify it as much as possible. A combination as such is rejected for use in educating students, because our initial request is not achieved, concretely making $5 \mathrm{D}$ project.

\section{Combination 3 - Revit + Gala +}

Microsoft Project + Navisworks

Creation process is as follows: making $3 \mathrm{D}$ model and bill of quantities using Revit, making cost analysis and bill of cost with Gala, preparing time plan with Microsoft Project and finally connecting all these parts in Navisworks, in order to obtain the purpose of the construction simulation with cost display. In the figure 4 we can see steps of combination 3 .
The combination was good because all the parts are accurately made, but the incompatibilities of software were observed. This is why we proceeded to the next combination in order to avoid the redundant software i.e. Microsoft Project.

\section{Combination 4 - Revit + Gala +} Navisworks

Creation process is as follows: creating a 3D model and bill of quantities using Revit, making bill of cost and time plan using Gala, exporting plan to .mpp format and connecting plan with the model and costs to make a $5 \mathrm{D}$ construction simulation using Navisworks. In the figure 5 we can see steps of combination 4 .

This combination worked well, showed the minimum of used software applications and the most effective results. 


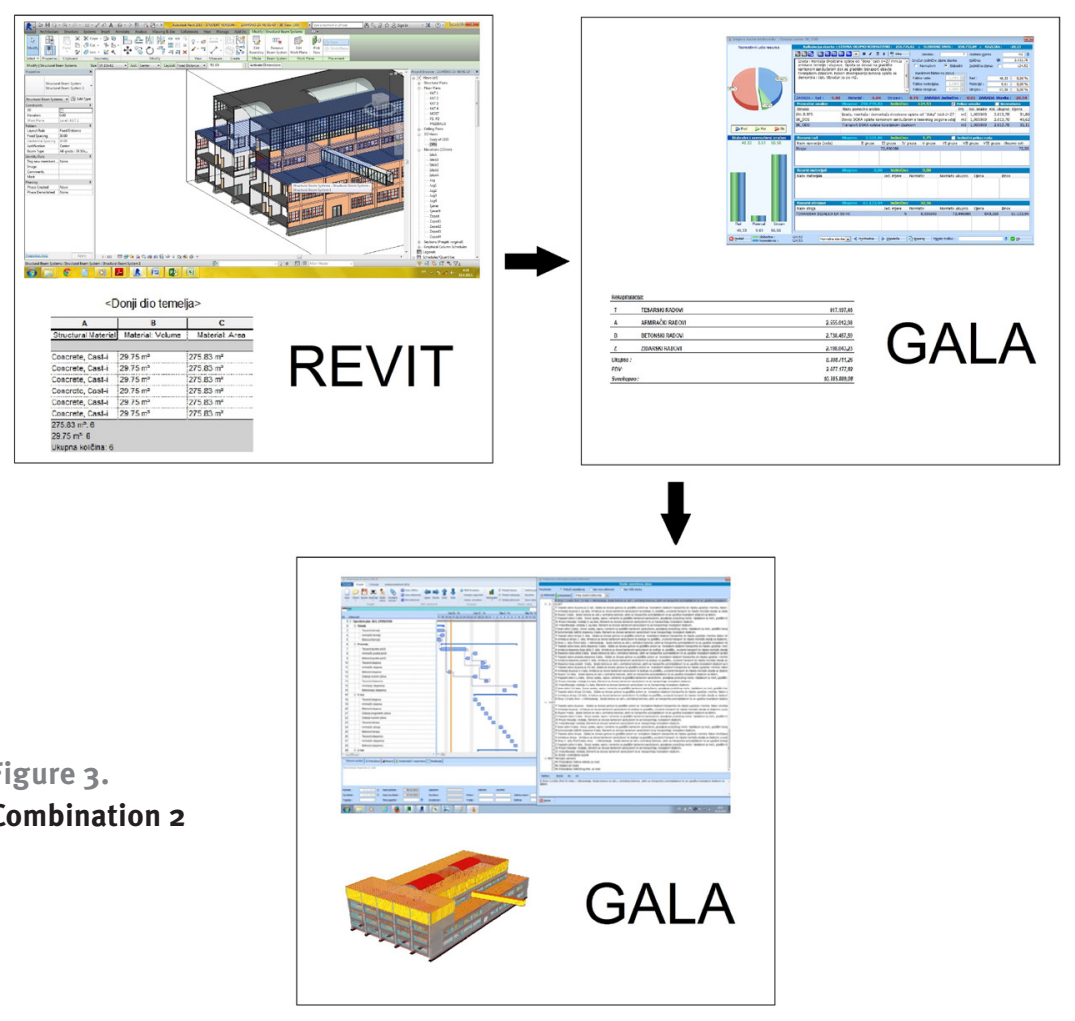

Combination 5 - Allplan + Gala + Navisworks

Creation process was as follows: creating a 3D model and bill of quantities using Allplan, making bill of cost and time plan using Gala, exporting plan to .mpp format and connecting plan with the model and costs to make a $5 \mathrm{D}$ construction simulation using Navisworks. In the figure 6 we can see steps of combination 5 .

The above combination was good for use in elementary education in BIM that shows the role of the IFC standard form model that is used for the transmission of information through a variety of software. Furthermore, the combination is a good example of making $5 \mathrm{D}$ project engineering, but as Revit found to be more compliant with the IFC export in GALA we stayed with the combination 4 .

With listed combination we identified advantages and disadvantages of individual software together with identification of their performance and use. Furthermore, we examined the transmission of IFC forms within the software and conclude that combination (Revit +
Gala + Navisworks) has proven to be the most appropriate for the application of $\mathrm{BIM}$ in education.

\section{Correct use of methodology on real example}

To illustrate the proper application of developed methodology we applied the same in the case of the Civil Engineering building in Zagreb. This example served as basic example for student assignments, but also as correct example of making $5 \mathrm{D}$ project for the participants who will eventually use them in practice.

3D model was made using Autodesk Revit software and is shown in figure 7. It was made as reinforced concrete structure that consists of the following elements: foundations, foundation slab, columns, lintels, ceiling and stairs while the walls are made of brick.

Bills of quantities were exported to .txt form also from Revit software. Its purpose is to show specific type of elements and their quantities and they are specially adapted to make cost analysis. Cost analysis and bill of cost were made using software Gala. After importing IFC model in Gala, we can mark the elements that will be used for a specific price analysis which automatically calculates the total amount of labeled elements. The schedule was made with Gala calculating with working groups, their number, out-turn and material quantities. Simulation of construction was made using Navisworks Manage software where elements of object where labeled to plan activity. In addition, cost was entered to each activity, in order to obtain a $5 \mathrm{D}$ project. In the end, we exported a video simulation that showed a real planned construction simulation.

\section{Models made for student case studies}

For the purpose of testing the methodology in education we made 15 models (figure 8) in Revit so that students could work in pairs solving their case studies based on the example of the building of Civil engineering faculty that we made. Students followed this phases except for first step-drawing 3D model in Revit because they would not have enough time and education in that short time to make the same so we had to prepare them instead. Therefore, they can start from the second phase-exporting bill of quantities. Each model building construction had elements that required the application of different norms when making cost analysis (concrete ring beams, columns, beams, slabs, foundations, lintels, slanted board, basic boards, stairs, concrete walls, partition to load-bearing brick walls). In doing so, we did not want to get students to focus on the shortcomings of the software but to obtain basic BIM skills.

\section{Validation Methodology Through \\ Results Student Surveys}

To validate the methodology we surveyed the students twice. First time before and second time after BIM education. Survey results indicate that most students before the education 


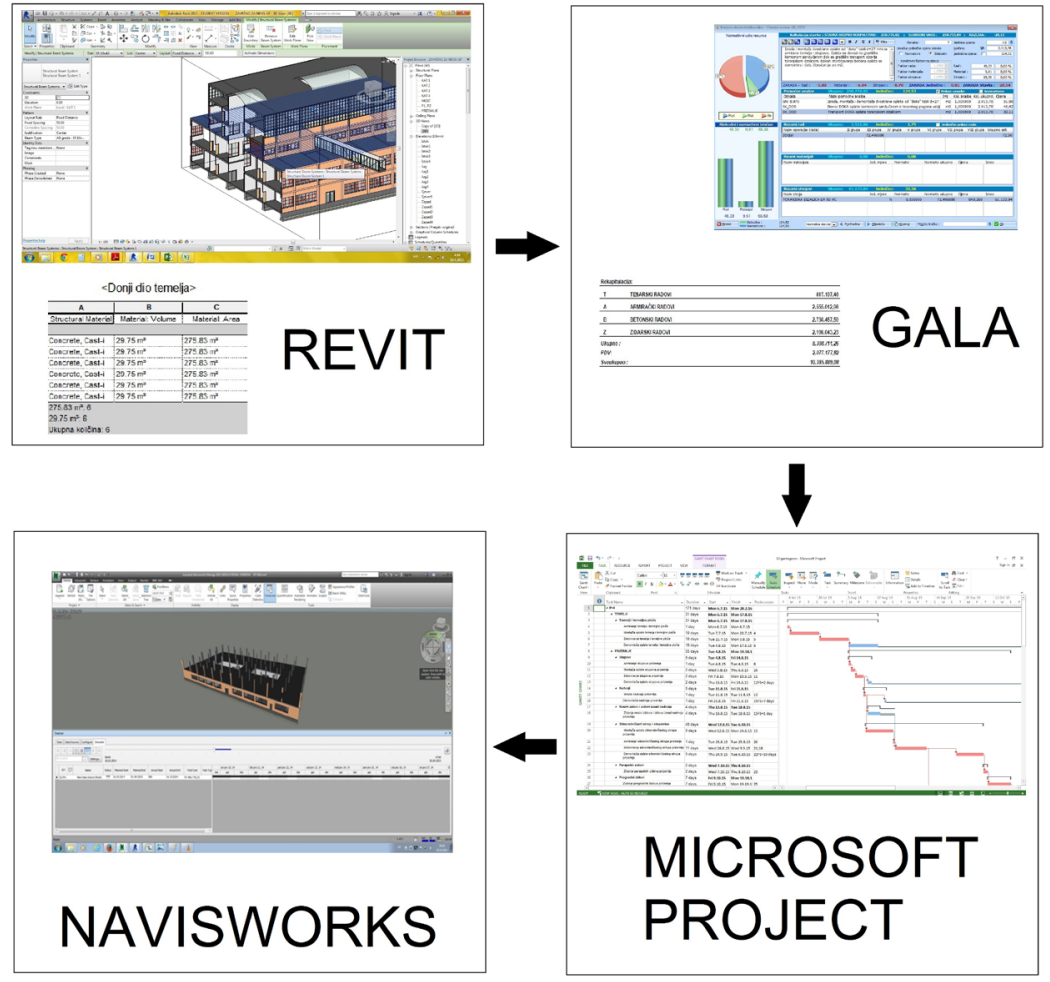

Figure 4. Combination 3
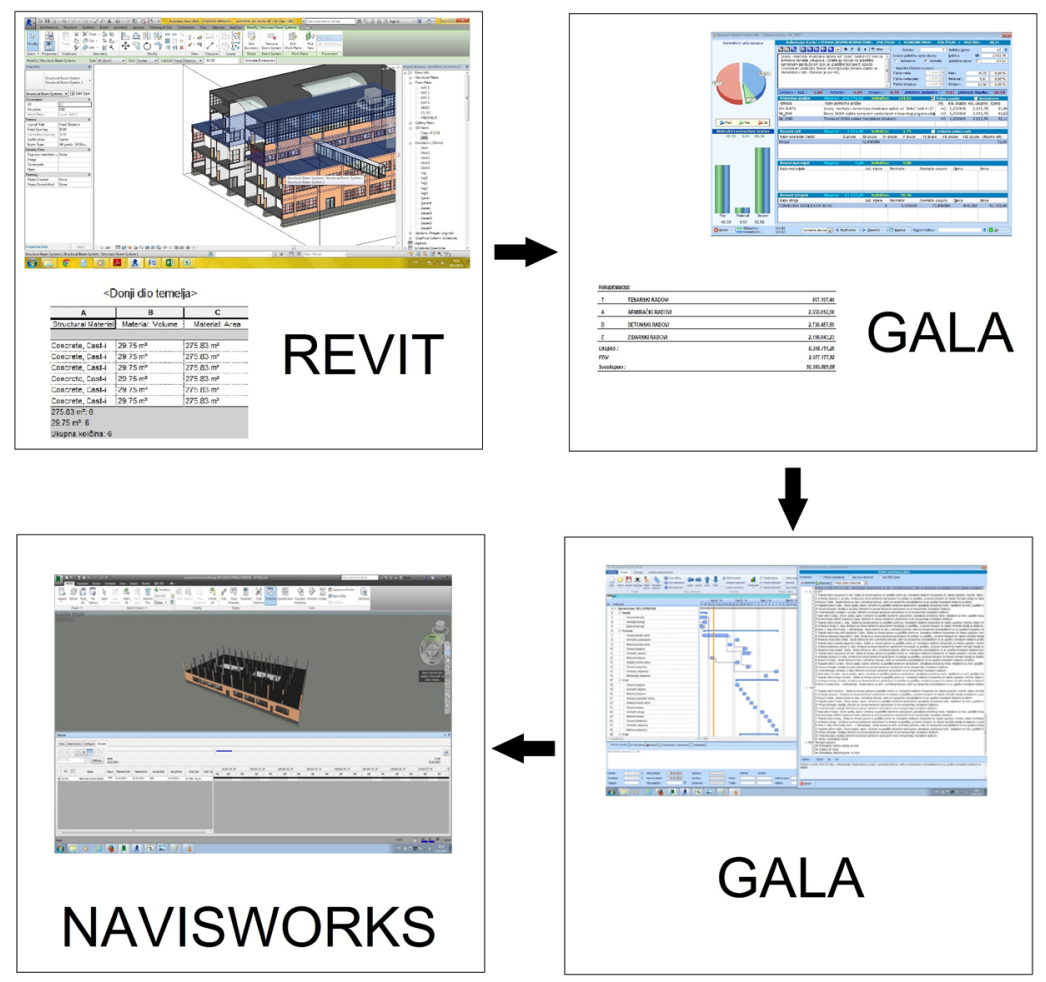

were not familiar (YES; 30\%, NO: 70\%) with the concept of BIM technology and after, with the help of adequate training that provided basic BIM knowledge, all the students gave a positive answer. In figure 10 the survey results also show that in the beginning students were not familiar with BIM software tools.

Only one student was familiar with Gala before making case study but after making their case studies, students were able to evaluate performance of Revit, Gala and Naviswork software. Generally, students were satisfied with the software which they applied for their case studies. Average evaluation of the same was following: Gala - grade 4, Revit - grade 3 and grade 4, Navisworks - grade 3 and grade 4, which means that students think that the performance of the software is quite satisfactory.

Furthermore the results have showed that Revit (software for creation 3D models and bills of quantities) had very good performance as evidenced by high survey scores. The ignorance was the reason for the occurrence of possible problems wherein the same can easily be solved with the help of vendors and professionals who use it. For Gala (software for cost analysis and time plan) we noticed lack of cooperation with elements after importing IFC model from Revit, therefore we had to insert quantities of some elements manually. Gala's original use was to calculate bill of costs the function where we could not have found. Furthermore, making the time schedule is not recommendable for more complex models, as it was in our case with the building construction. We can conclude that Gala's performance is not good enough for time planning and $4 \mathrm{D}$ simulation but it is excellent in cost estimation. Having a less complex projects, students could not make the same conclusion and the distinction but for less complex projects Revit and Gala were compatible. Student survey shows a very high grade for Gala. Then

Figure 5. Combination 4 


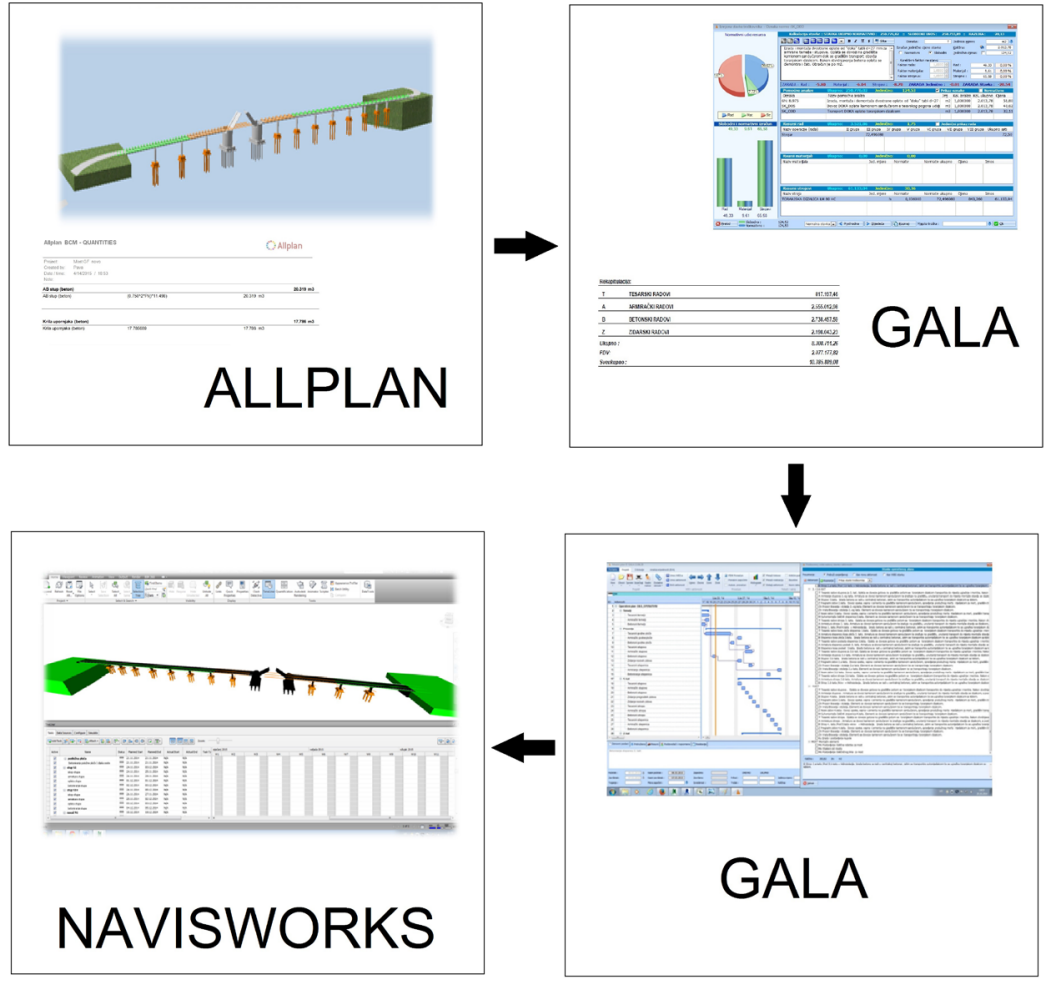

Figure 6. Combination 5

for Navisworks Manage (software for 3D model, time plan and cost connection) we noticed that schedule, cost estimations and $3 D$ elements need to be well planed and well suited before start of their connection. If all those parts are not well prepared and incompatible it requires additional work and

constantly returning to the first stage. Finally, the student survey showed a very high grade for Navisworks.

The results show that the methodology was successfully developed and applied to the education of students and as such can be applied in practice and the further stages of preparation

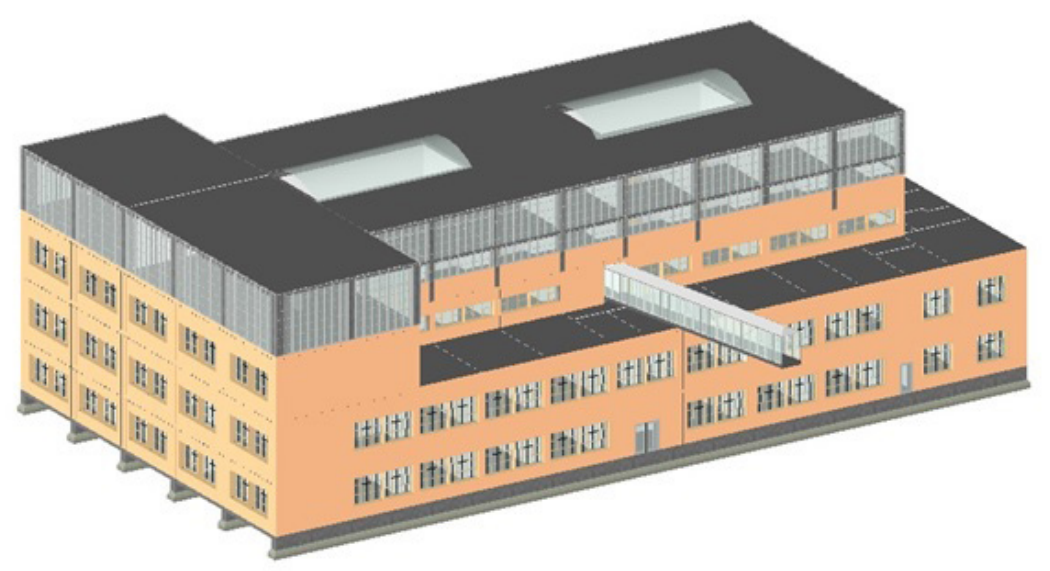

Figure 7.3D model of Civil Engineering building in Zagreb

and implementation of the project. Also it can be developed in education to a higher level on the required level of individual participants who will apply to the same.

\section{Conclusion}

In This Article We Have Shown That:

$\checkmark$ the proper application of BIM software and so far developed standards enables a company to achieve complete control of information and a number of benefits in the business for which is BIM continuously expanding its application and is experiencing considerable growth around the world countries,

Croatian construction companies are familiar with the term BIM technology, but they rarely applying the same in practice,

the developed methodology can be applied in practice, in the phases of preparation and execution of the construction project in order to achieve a better communication and cooperation between the participants.

All of the above confirmed the first hypothesis.

Also we have proved that:

the BIM education and its accessibility to the public is associated with greater awareness about BIM and a higher percentage of companies that use BIM and properly implement in their own operations

the students who used developed methodology improved: communication skills, critical thinking, the ability to perceive potential problems, a way of creative thinking in solving problems in a collaborative virtual environment which in the end allowed them to observe the consequences of each decision

the methodology that was developed and applied to the education of students has been proven as successful and as such can be used to further practice in the phases of preparation 

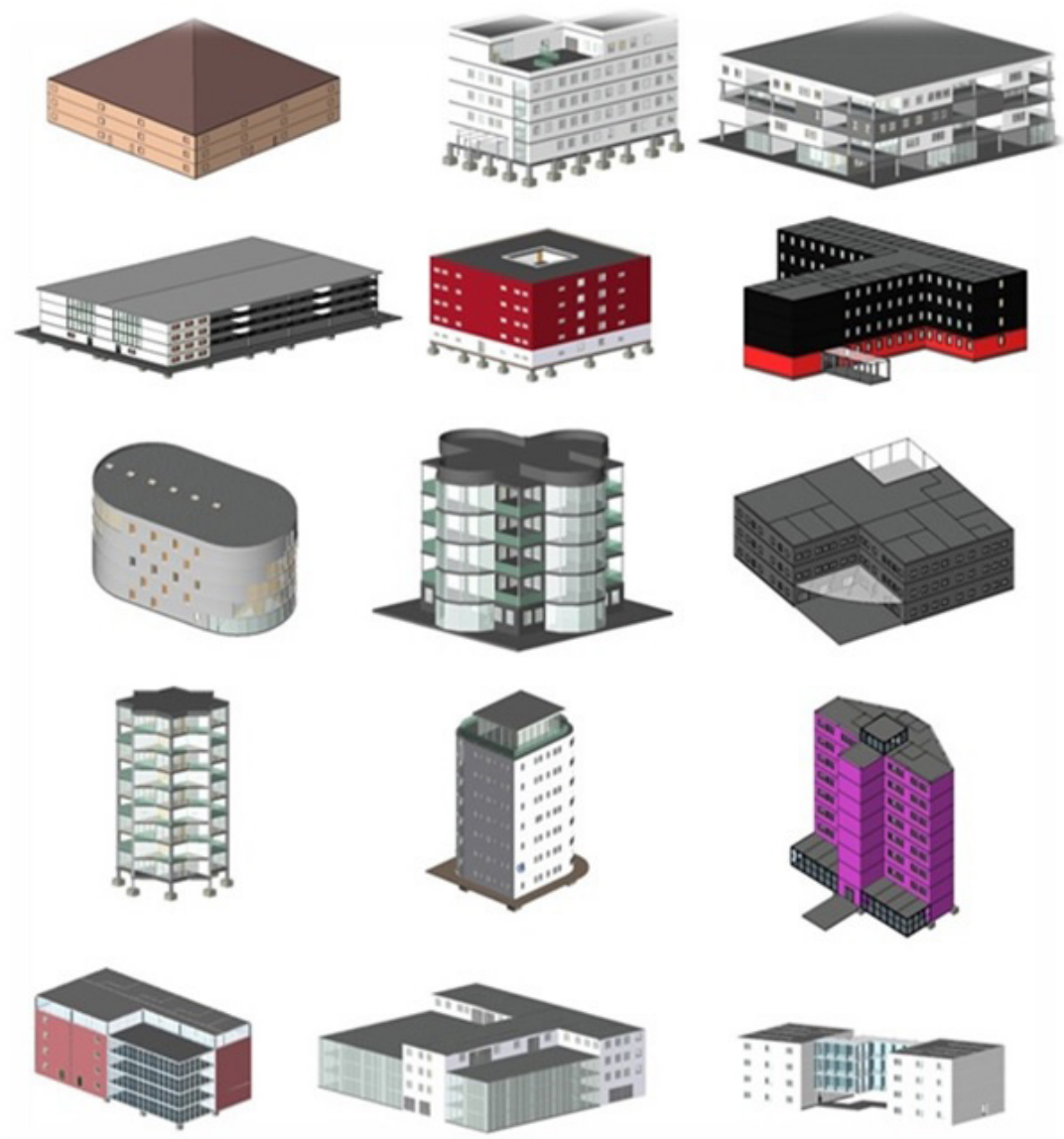

Figure 8. Models made in Revit for student education

and execution of the project, and develop its use in education, depending on the required level of individual participants who will apply the same

Therefore the hypothesis $\mathrm{H}_{2}$ is also confirmed.

So the developed steps (figure 10) that can be used in the preparation and execution of the project and thereby present BIM software are as follows:

1. preparation of $3 \mathrm{D}$ models using Autodesk Revit or Nemetschek Allplan software,

2. preparation of bills of quantities using the software Autodesk Revit or Nemetschek Allplan,

3. cost analysis using software Gala,

4. creation of schedule using software Gala,

5. preparation of the construction simulation with the display cost (5D project) using the software Navisworks.

The exchange model through the above software is done using a standard form of IFC model to achieve complete control of information, and the exchange of the time plan carries out as .mpp form.
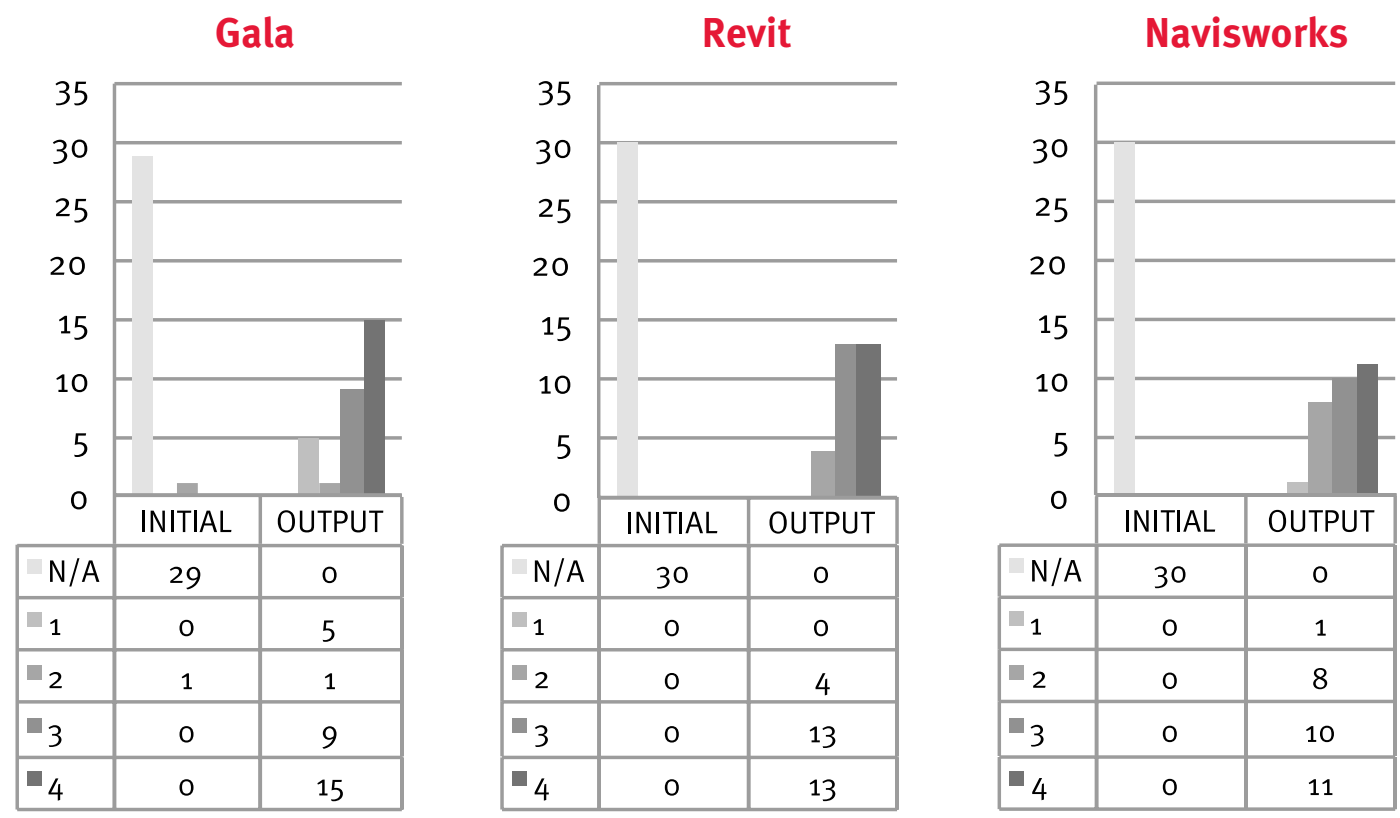

Figure 9. Graphical display of the initial and output survey responses on the question: 'Do you know this software? If yes, mark on scale 1 to 4 their performance ( 1 is bad performance, 4 is excellent performance).' 


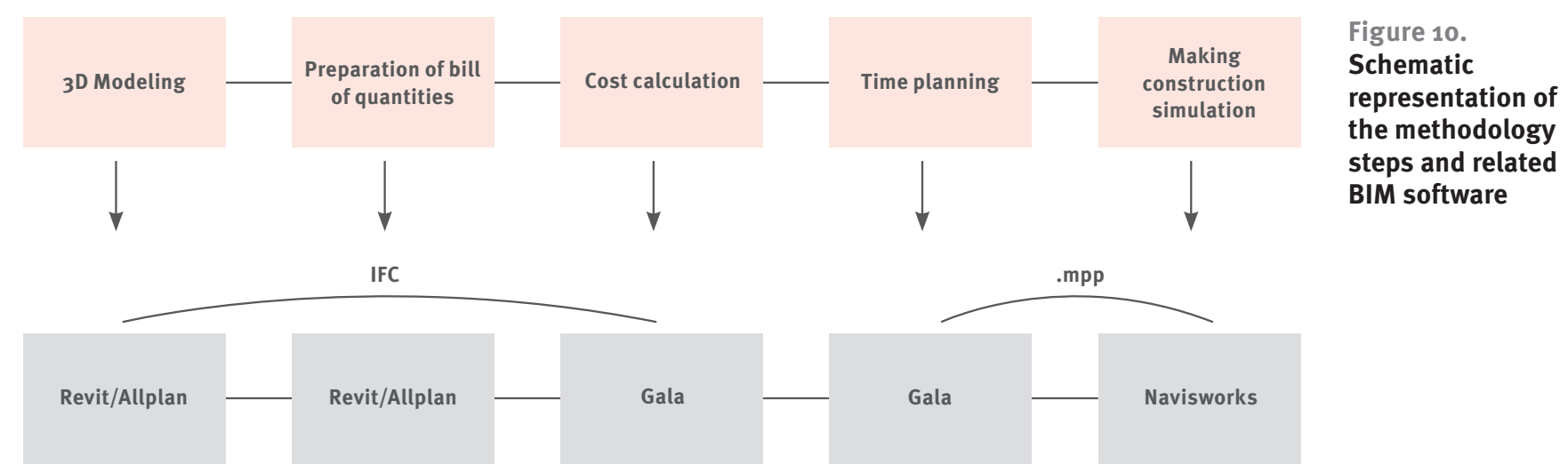

As discussed topics are just in their early development stage we propose the following research:

> inclusion of other BIM tools which would enable a development of a number of methodologies for the BIM implementation inclusion of additional resources (labour and equipment) in construction simulation

extending the BIM approach to the other courses at the Construction Management education

We hope that the methodology developed in this study will help to better the education of Civil Engineering students. Furthermore, we hope that this methodology will serve the practice through the project phases of preparation and execution.

\section{Acknowlegments}

Special thanks for contributing to this study goes to:

- Intelika for the given training, technical support for AUTODESK software Revit, models and simulations of construction in Navisworks Manage,

- company Baldini Studio for the given training and technical support for Nemetschek Allplan,

company Gala for given training and technical support in the software Gala.

Mr. Savo Klader, dipl.ing.građ for the given materials for making $3 \mathrm{D}$ model of Civil engineering building, the students of the first year of graduate studies of Construction organization at Civil Engineering faculty in Zagreb for taking part in the student survey,

the companies who were surveyed for the research of the Croatian market regarding opinion on BIM.

\section{References}

ARUP (2015.), Available on:〈www.arup.com〉 Visited: [23.4.2015.] buildingSMART, 2015. Available on:〈http://www.buildingsmart. org/about/about-buildingsmart/> Visited [6.3.2015.]

Cad Addict (2010.), Available on:shttp://www.cadaddict.com/2010/03/list-of-bim-softwareproviders.html> Visited: [28.4.2015.]

Dolaček Alduk, Z., Radujković, M., Vukomanović, M., (2012.), 'Primjena računalnih aplikacija za upravljanje projektima u građevinskoj industriji Jugoistočne Europe', ‘Tehnički vjesnik' 19 (2), 249-258

Eastman, C., Teicholz, P., Sacks, R., Liston, K. (2011.), BIM Handbook: a guide to Building Information Modeling for owners, managers, designers, engineers, and contractors, Second edition, Wiley, Canada

Elinwa, K. U., Agboola, O.P. (2012.), ‘Beyond BIM - A Classroom Approach To Virtual Design Education', 2nd World Conference on Education Technology Resarches, Wcetr, Procedia-Social Behavioral Sciences 83 (2013.) 393_397

Fonesca, D., Villagras, S., Marti, N., Redondo, E., Sancez, A. (2012.), 'Visualization methods in architecture education using $3 \mathrm{D}$ virtuial models and augumented reality in mobile and social networks', 3rd World Conference on Learning, Teaching and Educational Leadership, Wclta, Procedia-Social Behavioral Sciences 93 (2013.) 1337_1343

Friedrich, J., Kubečka K. (2013.), 'BIM - The Process Of Modern Civil Engineering In Higher Education', Wclta, Procidia-Social and Behavioral Sciences 141 (2014) 763_767

Fu, C, Aouad, G., Lee, A., Mashall-Ponting, A., Wu, S. (2005.), 'IFC model viewer to support nD model application'

Hill, T., Steele, R., (2014.), ‘ISO: Standards for BIM \&Infrastructure, Presentation to Government BIM Symposium'

Intelika BIM, (2015.), Available on: ‘http://www. intelika.hr/o-nama/183-bimvrijeme-novihtehnologija> Visited: [28.4.2015.] MacLennan, P., (2015.),' Crossrail and transport for London set out key milestones for 2015, Crossrail Ltd (CRL)'

Malachy, M. (2012.), 'BIM Collaboration in Students Architectual Tecnologist Learning', 'Journal of Engineering, Design and Techologiy', June 2013.

McGraw Hill Construction, (2013.), 'The Business Value of BIM for Construction in Major Global Markets', Smart Market Report

Peterson, F., Hartmann, T., Fruchter, R., Fisher, M. (2010.), 'Teaching construction project management with BIM support: Experience and lessons learned'

Studio Ars, (2015.), Available on:〈http://www. studioars.com/hr/view.asp? $\mathrm{p}=244 \& \mathrm{c}=17$ > Visited: [28.4.2015.]

Webb, S., (2015.), 'London's most boring project: f14.8bn Crossrail tunnel takes shape below capital but they've been going three years and are still only a fifth of the way through', Mail on line 